\title{
LA NOVELA REALISTA COMPROMETIDA Y LA NOVELA TESTIMONIAL EN LA ESPAÑA DEL SIGLO XXI
}

\author{
Milica Lilic \\ Universidad de Granada
}

\section{RESUMEN}

Debido a los cambios producidos en la realidad humana del siglo xxi, que implica un mundo mercantilizado y una generalización de los valores, pero también una visión individualista que produce enormes desigualdades económicas y sociales, la literatura actual se ha adaptado al nuevo escenario, manifestando los retos de la sociedad moderna. La narrativa espańola ha seguido esta tendencia de comprometerse con la realidad actual y dar cuenta de ella, creando novelas tanto de valor realista comprometido como testimonial. Ambas se caracterizan por su carácter de denuncia, con la diferencia de que los personajes y las acciones de las novelas testimoniales tienen un referente identificable fuera de la obra y la autenticidad de lo narrado puede revisarse, mientras que en un texto realista no es posible hacerlo. Aunque esta distinción no es novedosa, la modalidad de la novela realista comprometida y la testimonial en el contexto que implica la Espańa globalizada del siglo xxi cuenta con determinados rasgos particulares.

PALABRAS ClAvE: literatura globalizada, novela española actual, compromiso literario, novela realista comprometida, novela testimonial.

THE REALISTIC ENGAGED NOVEL

AND THE TESTIMONIAL NOVEL IN THE 21ST CENTURY SPAIN

\section{Abstract}

Due to the changes produced in the human reality of the 21 st century, which not only implies a merchandised world and a generalization of values, but an individualist vision that produces enormous economic and social inequalities, current literature has adapted to the new scenario, presenting the challenges of modern society. The Spanish narrative has followed this tendency to engage with the current reality and to account for it, creating novels of both engaging and testimonial value. Both are characterized by their denunciatory nature, with the difference that the characters and actions of the testimonial novels have an identifiable reference outside the work and the authenticity of the narrative can be revised, while in a realistic text it is not possible to do so. Although this distinction is not new, the modality of the realistic engaged novel and the testimonial novel in the context that implies the globalized Spain in the 21 st century has certain particular features.

KeYwords: globalized literature, current Spanish novel, literary commitment, realistic engaged novel, testimonial novel. 


\section{LA NOVELA ESPAÑOLA DEL NUEVO MILENIO}

El contexto que sobreentiende el siglo XxI (la sociedad de masas, los medios de comunicación altamente desarrollados y nuevos enfoques interdisciplinarios) permite establecer una correlación estrecha entre la globalización y la literatura, de manera que esta segunda cuenta con una serie de nuevos rasgos característicos: la presencia de un lector global, obras en distintos formatos y al alcance en cualquier situación, una amplia disponibilidad de los medios de difusión y las estrategias de mercado, y los elementos temáticos y formales que pretenden crear un discurso más amplio, vinculando distintas naciones que comparten temas del contexto histórico actual. Aunque este cambio de formas de creación y representación de un texto literario viene estrechamente relacionado con las transformaciones acaecidas en el espacio cultural y la lógica del mercado de los últimos años, Birus aclara que la globalización no ha provocado el deterioro de la literatura nacional en favor de la mundial. Al contrario, las presenta como dos procesos que se desarrollan de manera simultánea:

For what we meanwhile observe is not the replacement of national literatures by world literature, but the rapid blossoming of a multitude of European and nonEuropean literatures and the simultaneous emergence of a world literature (mostly in English translations) as two aspects of one and the same process (2003: 21).

Ante este contexto global que ha afectado a todas las esferas de la vida social -desde la política y la económica hasta la educativa y la cultural-, España ha ido atravesando una época de cambio y transformación. Es notable la apertura internacional que el país ha experimentado desde la llegada de la democracia, pero, por otra parte, durante la última década ha pasado por una profunda crisis, que no solo ha sido económica, sino también de identidad, esto es, una crisis que ha afectado en gran medida a todos los ámbitos de la sociedad: institucional, político, cultural y educativo. Tomando en cuenta esos nuevos contextos sociales y situándose entre lo local y lo global, el discurso literario actual no solo ha seguido las directrices de dichos cambios, sino que también ha conferido su definición propia, de tal forma que, en palabras de Navajas: «La ficción española narra desde hechos y perspectivas singulares, pero en íntima conexión con orientaciones generales» (2002: 80).

Como producto de esa compleja realidad pluridimensional nace la novela actual, que cuenta con una pluralidad de registros, de manera que no se puede hablar de una única tendencia ${ }^{1}$. Esa libertad de textos literarios proviene del posrealismo,

1 A mediados de los ańos 90 hubo un intento de agrupación de escritores jóvenes que nacieron en los años 70, realizado bajo el nombre Generación X. El escritor Douglas Coupland forjó la denominación del grupo con su novela homónima publicada en 1991, donde reflejó el estilo de vida y los pensamientos de los jóvenes occidentales que no habían conocido la guerra ni la posguerra y que se habían criado en una sociedad de consumo. El interés temático de estos autores, también denominados neorrealistas, se centraba en «la representación de la conducta de los entonces jóvenes adolescentes, sus salidas nocturnas en las grandes ciudades, el uso y abuso de drogas, del sexo, del alcohol y de la música rock» (Gullón 2006). A pesar del elevado número de lectores jóvenes conseguido, estas 
concepto usado por Gullón para determinar las novelas que exploran las relaciones humanas, la actitud y los valores de una persona fuera del marco al que se restringe la novela realista decimonónica. En ese sentido, este autor asegura que dicho fenómeno refleja, mejor que el realismo decimonónico, la situación social española:

... la Espańa de Franco, con su inevitable techo ideológico, marcó a varias generaciones, que ahora van equilibrando los años vividos bajo la dictadura con los pasados en democracia, lo que supone una enorme liberación. Este posrealismo va emparejado con un descenso de interés por el hiperrealismo propio de los escritores de la generación $\mathrm{X}$, aunque sus modos y métodos han sido asimilados, y permanecerá como una variante del realismo en el futuro (Gullón 2004: 4).

Esto, desde luego, no quiere decir que no hayan aparecido nuevos nombres, al contrario, se ha pasado «de una narrativa de resistencia y subsistencia a una narrativa de abundancia" (Alonso 2011: 24). Es decir, son tantos los nuevos autores que, junto con los más antiguos que siguen activos, crean una variedad y multiplicidad literaria, un abanico de tendencias tan variadas que no permiten establecer una línea dominante y prácticamente imposibilitan la labor de los historiadores y críticos de organizar a los autores actuales según criterios concretos. Lo que caracteriza a estos autores de los primeros años del siglo Xxi, según lo aclara Gullón, es que «... piensan, novelan menos la colectividad y se dedican más a atender lo personal» (2004a: 16).

Pero, además, aunque algunas obras se siguen escribiendo al margen de las condiciones impuestas por el mercado, en ciertos casos la definición tradicional del texto literario termina siendo sustituida por la del producto editorial. De hecho, la cultura de masas con sus exigencias, las leyes del aparato editorial español actual y la abundancia de premios literarios como estrategia de venta han afectado el nivel de calidad estética de algunas obras, de manera que «hemos pasado de la censura de la posguerra a la presentación de información filtrada por los intereses comerciales» (Gullón 2004: 2). Así se genera el boom de la novela comercial, esto es, el éxito de aquellas obras que satisfacen las demandas de un público poco exigente "que compra para consumir» (Gullón 2004: 3). Esto, a su vez, supone dos requisitos clave para la publicación de una novela: satisfacer las demandas del mundo de la cultura y las de la cultura de las masas. En ese sentido, Cortés (2002: 51) se atreve a afirmar que, mientras que en la época de la modernidad «la literatura es todo lo que se lea como tal», en la de la globalización «la literatura es todo lo que se venda como tal». Valls

obras no fueron bien recibidas por la crítica literaria, que, entre otras cosas, les reclamaba la falta de originalidad y la pobreza de lenguaje. En España, la publicación de Historias del Kronen (1994) de José Ángel Mañas obtuvo gran éxito entre la juventud lectora, que identificó su propia búsqueda de identidad con la reflejada en la novela. Aunque la mayoría de los escritores X ha seguido diferentes tendencias en el siglo XxI, en los 90 existía un grupo importante de los seguidores de Mańas: Ismael Grasa con De Madrid al cielo (1994), Benjamín Prado con Raro (1995), Caimán Montalbán con Bar (1995), Pedro Maestre con Matando dinosaurios con tirachinas (1996), Gabriela Bustelo con Veo, veo (1996), Daniel Múgica con La ciudad de abajo (1996), Lucía Etxebarría con Amor, curiosidad, prozac y dudas (1997), etc. 
incluso hace referencia a La sombra del viento (2001), de Carlos Ruiz Zafón, La catedral del mar (2006), de Ildefonso Falcones, y El tiempo entre costuras (2009), de María Dueñas, para ejemplificar el fenómeno mediático de las novelas que «... también desempeñan su papel en el sistema literario, pero es probable que tenga más que ver con el comercio, interior y a veces también exterior, o con las intrigas de determinadas capillas literarias, más que con la estricta literatura» (2016: 3). Esta postura la comparte Núñez, que deduce, en su estudio sobre los factores que homogeneizan la industria del libro y afectan a los hábitos de lectura, que «la conversión de la literatura en parte de una industria más general del ocio, [...] puede causar una perversa espiral de oferta y demanda en la que se irá anulando la cabida hacia otras opciones literarias» (2011: 49).

Como resultado de tal situación, aparece la trilogía de Agustín Fernández Mallo titulada Proyecto Nocilla, compilada de las novelas Nocilla Dream (2006), Nocilla Experience (2008) y Nocilla Lab (2009). Su influencia se refleja en la producción de otros autores en esos ańos, cuyas novelas comparten algunos de los recursos formales: la superposición de varios géneros literarios, la fragmentación temporal y espacial de la narración y el uso de las nuevas tecnologías. Así, la agrupación formada por Vicente Luis Mora con Circular 07 (2007), Juan Francisco Ferré con La fiesta del asno (2005), Manuel Vilas con España (2008), Jorge Carrión con La brújula (2006) y Robert Juan Cantavella con Proust Fiction (2005), según lo aclara Pantel (2016: 34), se refiere a determinadas obras y no a sus autores, por lo que es más apropiado denominarla «narrativa mutante» que "generación Nocilla». De cualquier forma, esa «etiqueta generacional desapareció con rapidez de la prensa digital y especializada precisamente por no corresponder a mucho más que a una campaña de promoción comercial» (Pantel 2016: 34).

El inicio del siglo XXI introdujo nuevas modas literarias, como la ficción documental, la novela romántica, la experimentalista, la erótica, la fantástica o la del terror (Alonso 2011: 29), generando así una cierta libertad estilística y variedad estética, así como la simultaneidad de escritores de varias generaciones que no forman un grupo homogéneo ni unitario, sino que publican obras de muy distinto alcance e interés (Valls 2003: 27) ${ }^{2}$. Además, Champeau (2011: 13-14) destaca que en la actualidad la literatura transgrede las fronteras, tanto discursivas y genéricas como semióticas, de manera que la oferta narrativa actual oscila entre posibilidades diversas. Esa heterogeneidad de fuentes y técnicas proviene de la conexión que las nuevas poéticas españolas del siglo XXI tienen con

... corrientes europeas y, muy en especial, norteamericanas y la adaptación integral de formatos y materiales procedentes de internet, de la música pop y rock, del cine

2 En los años posteriores, en la introducción al número monográfico dedicado a La nueva novela española actual (1995-2015): descubrimientos, perplejidades y estrategias de Ínsula, Valls explica que el término de «nueva novela española actual» tratada en la revista se limita «... a aquellas obras de autores que empiezan a publicar no antes de 1995, pero que el conjunto de su producción novelesca se da a conocer en el siglo XxI» (2016: 2). 
de género y subgénero [...] y, en suma, de los medios audiovisuales en que han crecido, incluidas las series televisivas infantiles y de adultos, la iconografía de la sociedad de consumo, los personajes y espacios de la industria del entretenimiento y a menudo los fetiches diseńados en ese universo que pueden ir desde Madonna a los cargantes politonos de los teléfonos móviles (García y Ródenas 2011: 969).

Así, lo que caracteriza a la narrativa española actual es la «búsqueda incesante de nuevos caminos, de nuevos procedimientos para mostrar la nueva realidad, la del momento, cada vez más compleja y fluctuante» (Valls 2003: 36). Esa nueva realidad del siglo xxi, con los inevitables efectos de la globalización y el boom tecnológico, queda reflejada en Cicatriz (2015) de Sara Mesa, obra que muestra el fomento de la vida virtual frente al contacto directo y la carnalidad, retratando a una pareja que inició su relación virtual en un foro de internet. Es una reflexión de la sociedad de consumo, pero también del individualismo y el aislamiento como una de las consecuencias directas de la globalización y el uso excesivo de tecnología. Asimismo, Marina Perezagua construye en Yoro (2015) una trama global que se desarrolla entre Japón, África y Nueva York, mientras que los episodios en Brilla, mar del Edén (2014) de Andrés Ibáñez se extienden por Estados Unidos, la India, Japón y México y son casi novelas en sí mismas. Germán Sierra, por su parte, basa la historia de Intente usar otras palabras (2009) en Google. Internet y el ciberespacio también tienen una fuerte presencia en Lo mejor que le puede pasar a un cruasán (2001) de Pablo Tusset. Por otra parte, compitiendo contra la globalización, Lara Moreno en Por si se va la luz (2013) plantea la historia de un grupo que decide huir de todo lo que supone la civilización, viviendo solo de y por la naturaleza, de manera que la novela acaba siendo «una alegoría de la supervivencia por la dureza de lo que llamamos natural» (Pozuelo Yvancos 2016: 10).

Una de las novelas que han marcado lo que llevamos del tercer milenio es Tu rostro mañana (2009), la obra cumbre de Javier Marías, compuesta de tres novelas publicadas previamente (Fiebre y lanza en 2002, Baile y sueño en 2004 y Veneno y sombra y adiós en 2007), donde el autor «replantea la violencia como un problema ético y universal, y [...] también como una responsabilidad literaria» (Scharam, 2013: 55). Su importancia en la extensa narrativa de Marías queda reflejada en palabras de Pozuelo Yvancos: «... es como si toda la obra anterior de Marías hubiese sido preparatoria de lo aquí alcanzado» (2014a: 39). El reino de Celama (2003) de Luis Mateo Díez también reúne tres novelas (El espíritu del páramo de 1998, La ruina del cielo de 1999 y El oscurecer de 2002), a las que el autor añade también dos apéndices: Vista de Celama en 2003 y El sol de la nieve o el dia en que desaparecieron los niños de Celama en 2008. Una de las razones del gran éxito de esta trilogía sobre el territorio imaginario de Celama es

... haber transcendido su significación, esto es, haber logrado que se realice la transposición metafórica que tiene su eje en el estatuto simbólico de la significación, por el cual una cosa (un mundo particular con un origen delimitado, ese espacio rural definido) es capaz de decir el general de la condición humana, más allá de sí mismo, pero atravesando su raíz (Pozuelo Yvancos 2014a: 12). 
Considerando la novela un medio apropiado para la exploración de la sociedad y de la cultura contemporáneas, y observando únicamente la relación que se establece entre los fenómenos sociales narrados en una obra y sus rasgos ficticios, es posible establecer una distinción principal entre dos tipos de novelas actuales de carácter crítico: las que basan sus historias en dichos fenómenos sociopolíticos que afectan al mundo contemporáneo, pero cuentan con tramas y personajes inventados, y las que cuentan historias auténticas y personales sobre ciertos desafíos de la sociedad moderna. Sin embargo, esta distinción no es novedosa, ya que en épocas anteriores (especialmente en los años 60 y 70) y en distintas regiones (América Latina y Estados Unidos, entre otras) se escribían obras de valor realista comprometido, por una parte, y testimonial, por otra.

\section{EL COMPROMISO EN LA NOVELA REALISTA ACTUAL. RUPTURA (NO) DEFINITIVA CON EL SIGLO XX}

Según aclara Mainer, «el realismo no es tanto la voluntad de copiar de la realidad como de conseguir "un efecto de realidad"» (2005: 262). Precisamente por eso, el escritor se apoya en una serie de técnicas para dar sensación de verdad y solidez de una realidad creíble: «The similarity between sign and represented content is addressed by realists through a series of concepts like transparency, verisimilitude, naturalness, iconicity, resemblance, correspondence, and so forth" (Ronen 2010: 488). Además, procura presentar algunos elementos del mundo real (el entorno y el tiempo, el lenguaje, personajes históricos, datos estadísticos, entre otros) que le sirven para convencer al lector de la veracidad de todo lo relatado.

Aparte de estas características, aparecen la intención crítica y el componente ético como elementos clave, tratándose, pues, en este caso, de la novela realista comprometida que

... posee unos rasgos específicos que dimanan de la actitud del autor frente a la sociedad de su tiempo y del valor que se le asigna a la obra artística como instrumento para transformar la realidad histórica; la novela es, en estos casos, la expresión de la actitud del escritor ante las condiciones en que viven determinados sectores sociales de su tiempo; una situación que puede ser muy variada, por ejemplo, de explotación laboral, de miseria económica, de opresión política, de intolerancia en lo ideológico... Ante las circunstancias que tiene que soportar un amplio grupo de conciudadanos, el escritor, hombre de su tiempo, tras sentir profundamente los problemas, reacciona y trata de que se modifique esa situación conflictiva, onerosa, por los medios que tiene a su alcance y, entre ellos, principalmente por la ficción novelesca. Le da, pues, a ésta una transcendencia grande al convertirla en un medio para despertar en el lector la conciencia crítica ante el panorama que le circunda (Castañar 2001: 158).

Es decir, la literatura comprometida refleja la postura del autor con respecto a las principales cuestiones sociales. "A committed or engagé writer (or artist) is one who, through his work, is dedicated to the advocacy of certain beliefs and pro- 
grammes, especially those which are political and ideological and in aid of social reform» (Cudoon 2013: 139), de tal manera que, al exponer los inconvenientes a través de sus escritos y seńalar las acciones apropiadas que conducen al cambio, se convierte en un líder intelectual.

Siguiendo el desarrollo de la novela española en los últimos cincuenta años, se observa que entre 1960-1970 predominaba un alto grado de realismo, que en los años posteriores fue decreciendo a favor de las novelas de corte literario, «y que ahora vuelve a subir en busca de una ficción con mayor contenido de verdad» (Gullón, 2004a: 17). Tales novelas, con las cuestiones de fondo relativas a conflictos y preocupaciones de la sociedad, vuelven a cultivarse a finales del siglo xx, aunque en esta época, según afirma Martínez Cachero, «con mucha frecuencia se rehúye el tratamiento de aquellas [cuestiones] que, como la droga, el paro, el terrorismo, la emigración ilegal, etc., constituyen otras tantas graves lacras sociales que se soslayan -aunque hay excepciones- en virtud de una especie de conjuración del silencio» (1997: 489).

En cualquiera de estas épocas, las novelas comprometidas solían reflejar la realidad inmediata y hablar del tiempo contemporáneo al autor. En ese sentido, la escritura comprometida del siglo anterior tenía un papel importante en la generación de la conciencia nacional. En España ese fuerte nacionalismo literario lo explica Navajas, señalando que «la cultura española -hasta el pasado reciente- ha estado sobredeterminada, más que otras, por la circunstancia nacional y ha aspirado sobre todo a explicarse con relación al referente local más que al internacional y extranacional» (2005: 256). Esto quiere decir que dicha transformación literaria característica del siglo XXI no ha sido absoluta, ni se ha cortado definitivamente la relación con los temas que preocupaban a la sociedad en el siglo anterior. Al contrario, en paralelo con el proceso globalizador se ha establecido un «... contexto nacional de reapropiación de la historia del pasado siglo que invita a los escritores a remozar el concepto de compromiso literario» (Champeau 2011: 9). Entre los escritores que siguen manteniendo el interés en el pasado y en los temas de corte nacional y que, usando historia y hechos reales como premisa básica de sus obras, sitúan sus tramas en los años de la Guerra Civil $^{3}$, están Antonio Muñoz Molina con su novela La noche de los tiempos (2009), Isaac Rosa con ;Otra maldita novela sobre la Guerra Civil! (2007) o Javier Cercas con Soldados de Salamina (2001). Pozuelo Yvancos explica el gran éxito de esta última:

La literatura, la novela, encuentra aquí la posibilidad más noble de su existencia: ser testimonio de vida, y memoria de lo que ha sido la tragedia más grande que ha vivido España y que tiene que reescribirse desde el emocionado reencuentro con los verdaderos héroes (que fueron víctimas), encuentro que reflejan las páginas

3 Pozuelo Yvancos (2014a: 294-297) ofrece cuatro razones concordantes por las que la Guerra Civil ha obtenido tanto protagonismo en las novelas del siglo xxi: la importancia del memorialismo y los testimonios del yo en la cultura presente española; el empuje general de la novela histórica en los últimos años; las consecuencias de aquella época en actuaciones políticas de la España de hoy; y la extensión del tema de la Guerra Civil, ya que la vivió casi cada familia española. 
finales de la novela, llenas de emoción y dramatismo, que ningún lector puede olvidar (2014a: 317).

Asimismo, el tema de la guerra, aunque se trate de la Segunda Guerra Mundial, aparece en Medusa (2012) de Ricardo Menéndez Salmón, en Paris suite: 1940 (2007) de José Carlos Llop o en Lo que esconde tu nombre (2010) de Clara Sánchez, donde la autora, basando su argumento en las noticias de periódicos, habla de los antiguos nazis que podrían estar viviendo su vejez en el anonimato en la costa mediterránea. Menéndez Salmón, además, considerando necesaria la dimensión ética de la literatura, publica la llamada Trilogía del Mal (La ofensa en 2007, Derrumbe en 2008 y El corrector en 2009), como reacción contra indiferencia y como manifestación del poder del escritor en la esfera sociopolítica. Las obras como El nombre de los nuestros (2001) de Lorenzo Silva y Velódromo de Invierno (2001) de Juana Salabert también procuran recuperar y mantener viva la memoria histórica (del Desastre de Annual y del Holocausto, respectivamente), mientras que la novela El vano ayer (2004) de Isaac Rosa ofrece una aproximación al franquismo. Bernardo Atxaga, por su parte, en El hijo del acordeonista (2003) vincula una historia generacional sobre la memoria, la nostalgia y la amistad al periodo desde el «... nacimiento de ETA durante el franquismo hasta el desengaño presente de sus propios militantes» (Pozuelo Yvancos 2014a: 298). Ignacio Martínez de Pisón es otro de los escritores que se caracterizan por escribir novelas que «... trazan un dibujo en que casa muy bien lo interior y lo exterior, lo psicológico y lo social, la historia familiar y la crónica política, hasta lograr un cuadro muy coherente de la vida sentimental y política de la España de la segunda mitad del siglo XX» (Pozuelo Yvancos 2014a: 365). Ese es el caso de su novela El día de mañana (2011), que retrata la vida de los españoles en los últimos años del franquismo y durante la transición. El tema de la España recién salida de la dictadura aparece como fondo de la historia de Así empieza lo malo (2014), donde Javier Marías presenta la desdicha de una pareja conyugal iniciada por un secreto del pasado, abriendo un enfoque más amplio y cuestionando las consecuencias del pasado colectivo del país. Alfons Cervera publica Las voces fugitivas (2013), una novela total que reúne cinco novelas del ciclo de la memoria (El color del crepúsculo, Maquis, La noche inmóvil, La sombra del cielo y Aquel invierno), cuyos personajes e historias se entremezclan, dándole un sentido de totalidad al texto.

Este tipo de realismo comprometido se ve reflejado también en Espuelas de papel (2004) de Olga Merino, donde la autora habla de las emigraciones de los andaluces a Barcelona en los años 50, o bien en Safarad (2001) de Antonio Muñoz Molina, que mezcla personajes y hechos históricos y ficticios, presentando una vigorosa denuncia contra toda la marginación y violencia del siglo xx. Siguiendo la misma línea, Mariano Sánchez Soler publica El asesinato de los marqueses de Urbina (2013), donde, desde la ficción, procura desvelar el móvil económico y la oscura maquinación financiera de uno de los crímenes más famosos de la España de los años 80.

Algunas novelas actuales adoptan particularidades del contexto sociopolítico y cultural de la Espańa del siglo XXI, pero narran sobre los efectos de la época anterior de la historia del país, marcada por el franquismo y la transición, permitiendo que se lea el pasado desde el presente: 
La mayor parte de ellas proclives a hacer un balance de época, pueden también considerarse balance generacional de novelistas cuya juventud coincide con los últimos ańos de la dictadura de Franco, y que veinticinco años después, están en condiciones de tematizar resultados reales de esperanzas reales (Pozuelo Yvancos 2014: 439).

Así, en los primeros años del presente siglo se ha publicado en España una serie de novelas que muestran una decepción por la transición que rompió las ilusiones del pueblo. Ese nexo directo entre la actualidad y los últimos ańos del franquismo lo consigue Rafael Chirbes, quien en Los viejos amigos (2003) reúne treinta años después en una cena a los miembros de una célula comunista. Todos estos personajes son también narradores que cuentan el tránsito de la vida que llevaban antes, lo que, a su vez, constituye un desorden cronológico y crea una historia colectiva de la época. Además, guiado por el sarcasmo implícito del autor, el lector conoce a toda una gama de personalidades que en realidad presentan una crítica al sistema. Tanto en esta como en su otra novela Crematorio (2007) «a la luz del presente en el que se sitúa la historia y que coincide con el tiempo de la escritura, se evidencia la hipocresía de los compromisos pasados, dado que todos los personajes que tuvieron sueńos revolucionarios se adaptaron al nuevo sistema después de la vuelta a la democracia» (Orsini-Saillet 2011: 83).

La temática de la Guerra Civil y la Posguerra con proyección hacia el momento presente queda reflejada también en Los libros arden mal (2006) de Manuel Rivas, Llámame Brooklyn (2006) de Eduardo Lago y El corazón helado (2007) de Almudena Grandes. La publicación de este último libro inició la temática de la resistencia antifranquista en la obra de Grandes, reflejada en el ciclo de seis novelas titulado Episodios de una guerra interminable. Hasta la fecha se han publicado cuatro de ellas (Inés y la alegria, El lector de Julio Verne, Las tres bodas de Manolita y Los pacientes del doctor Garcia), quedando pendientes La madre de Frankenstein y Mariano en el Bidasoa. Cada entrega es una historia independiente, pero con algunos personajes compartidos y 1964 como el año cuando acaba la trama de cada una de ellas.

A diferencia de estos autores actuales que cultivan la literatura comprometida basándose en la historia nacional o mundial, es decir, que reinterpretan el pasado, otros pierden ese interés explícito en lo local y en representar su propia imagen identitaria. De hecho, se implican directamente en la problemática del presente «sometiéndola a una reflexión personal e independiente, libre de dogmatismos, escribiendo creaciones de clara actitud comprometida, trabajos narrativos no históricos, pero sí sobre la historia» (Moragues Chazarra 2013: 749-750), de manera que el lector puede detectar la postura del autor en cuanto a un determinado tema y localizar diferentes referencias en la sociedad actual. Además, bajo la influencia del proceso globalizador, estos autores se alejan de la representación de su espacio nacional y se centran en los problemas sociopolíticos y económicos que afectan a la sociedad a nivel internacional, por lo que este tipo de novelas «tiende a dar cuenta no tanto de una sociedad nacional como de una sociedad mundial. Sus estrategias narrativas y estilísticas así como sus temas y símbolos ya no contarán la historia íntima de las naciones, sino la del mundo» (Castany Prado 2007: 171). La temática se ha vuelto 
múltiple y plural, y los desafíos del mundo moderno, como es la crisis económica, las migraciones o la violación de las normas y los derechos en el ámbito laboral, urgieron a los escritores a dar su particular versión de los hechos. Esta tendencia de la «reinvención de la novela social», como la denomina Basanta, se caracteriza por

... la reactualización de la novela social, empezando por la reivindicación de la narrativa de los ańos cincuenta y del realismo como técnica privilegiada para mostrar y denunciar la situación social y económica presente a partir del compromiso ideológico de sus autores [...]. Estas novelas de fuerte indagación crítica coinciden en su preocupación por la sociedad de nuestro tiempo y del pasado inmediato con el fin de dar cuenta de la crisis generalizada de los últimos años, valiéndose del documentalismo y el testimonialismo críticos, del compromiso ideológico y político... (2016: 4).

Así, Belen Gopegui, una de las autoras más representativas de esta tendencia, escribe Lo real (2001), donde, partiendo de una base real (el caso Matesa, la transición democrática, el PSOE, la UCD, la televisión privada, etc.), introduce los elementos ficticios para alcanzar el grado de verosimilitud necesario para denunciar y criticar la realidad social en el mundo laboral actual. En 2014, esta autora publica El comité de la noche (2014), un thriller social con la corrupción y la industria farmacéutica de fondo. Juan Bonilla publica Los príncipes nubios (2003), novela de denuncia social sobre la inmigración y la explotación humana, centrada en una red internacional de mercancía sexual. En Piel de lobo (2016), Lara Moreno procura denunciar la naturalización de la violencia sufrida por las mujeres, tanto en su núcleo familiar como en su entorno.

Siguiendo esa línea, en 2016 se publica Patria de Fernando Aramburu, que abarca el período desde el posfranquismo hasta el abandono definitivo de las armas de ETA en 2011 y narra la vida en una comunidad de Euskadi marcada por el fanatismo ideológico y político. Marta Sanz, por su parte, escribe Farándula (2015), donde profundiza en el tema de la crisis de los últimos años y la desigualdad social, "haciendo gala de la sátira, la ironía, el humor y la deformación esperpéntica, para realzar trampas y miserias por las que se mueve la realidad de nuestro tiempo" (Basanta 2016: 4). De igual forma, Isaac Rosa, otro de los cultivadores de la narrativa comprometida, en La mano invisible (2011) denuncia la deshumanización y la explotación en el mundo laboral, mientras que en La habitación oscura (2013) critica la apatía, la incompetencia y la falta de compromiso de las generaciones jóvenes. Una aproximación precisa al precariado la propone Elvira Navarro en su novela La trabajadora (2014), donde pone énfasis en la relación entre los trastornos psíquicos que sufren sus protagonistas y la precariedad laboral en la que viven. Otros autores que escriben sobre los problemas relacionados con la crisis económica y social son Ginés Sánchez con Entre los vivos (2015), Pablo Gutiérrez con Democracia (2012) y Miguel Ángel Ortiz con La inmensa minoría (2014).

Por equivocación, el compromiso social de la literatura actual puede confundirse con «... la réplica de lo real y con las historias coetáneas, cercanas y familiares, con las que pueden identificarse los lectores» (Alonso 2011: 26), cuando en realidad ese compromiso es de carácter colectivo. 
Teniendo en cuenta lo expuesto, se concluye que el papel social de la literatura del siglo XXI se desarrolla en dos principales corrientes: la que evoca el pasado y la que se centra en la actualidad. En cualquiera de los casos, se trata de un discurso de utilidad política y social. En ese sentido, destacan dos tendencias complementarias que dominan el panorama literario de la España actual: «El regreso de los realismos y el final de la hegemonía de los discursos de ficción» (Carcelén 2011: 51), estableciendo nuevamente una conexión entre el texto literario y la realidad y replanteando la cuestión del compromiso. De esta manera se puede considerar que, según concluye Florenchie:

... asistimos al mismo tiempo que a una vuelta del compromiso, bajo la forma de una escritura responsable, a una vuelta al realismo. Ya no se trata de un realismo social o dialéctico, sino de un nuevo realismo, un realismo asentado en el "pacto de responsabilidad» [...], es decir, -aunque la expresión sea un poco redundante-, un realismo responsable (2011: 148).

\section{LA MODALIDAD CONTEMPORÁNEA DE LA NOVELA TESTIMONIAL EN ESPAÑA}

Estando en contacto con numerosos contextos y géneros extralingüísticos, la novela a veces sufre modificaciones y adopta otras características en tal medida que resulta difícil definirla exactamente. En ese sentido, es quizá la novela testimonial, es decir, «la no-ficción [...] la forma donde toda línea divisoria parece más cuestionada: las dicotomías señaladas que surgen cuando se intenta definirla están originadas en esa imprecisión de sus márgenes» (Amar Sánchez 1992: 20). Por ello, hay que tratarla como un discurso narrativo que procura evitar clasificaciones radicales y donde se observa una fracción y renovación simultánea de los rasgos de esas dicotomías (basadas en la relación entre técnicas-temas, forma-contenido, hechoficción), de manera que sus límites se vuelven imprecisos. Con la disolución de esos límites, se disuelven también los límites geográficos, aunque con determinadas peculiaridades del género en cada zona.

Sin embargo, lo cierto es que todas estas modalidades comparten la misma naturaleza; aunque los datos, personajes y acontecimientos de estas novelas pertenecen a la realidad histórica, es decir, aunque su contenido es puramente realista, la forma que obtienen en un texto literario siempre es una modalidad «fingida» de esa realidad. Esto quiere decir que, según afirma Sobejano, la novela testimonial siempre ha sido una representación de «un mundo histórico-social actual, atenta a las relaciones y circunstancias que forman lo que Hegel llamaba la prosa de la vida real» (1986: 91). Así, por una parte, este tipo de novelas aspira a ofrecer al lector una visión global del hecho ocurrido y convencerle de la autenticidad de los acontecimientos y, por otra, integra técnicas de ficción a fin de facilitar la lectura y mantener la atención del lector. Esa conexión entre objetividad periodística y subjetividad ficticia crea esa ambigüedad del género, estimulando su carácter informativo, pero sin quitarle sus rasgos novelísticos. 
Además, la novela testimonial podría interpretarse como una alternativa al relato realista, puesto que surgió justamente porque ya no bastaba con contar con el «reflejo de la realidad» y partir de los elementos documentales para construir una obra en la que el narrador y el argumento eran ficticios. Se necesitaba la realidad misma que informaba de los cambios producidos en la sociedad.

Aunque el género en cuestión suele nacer en épocas de censura y opresión, su existencia en el escenario europeo del siglo xxi también es posible y realizable, ya que, aunque aparentemente existe plena libertad de expresión, «la información que transmite la prensa más libre jamás hará inútil el testimonio de la novela. La prensa informa y enjuicia provisionalmente, de un día para otro, sobre la realidad; la novela no informa sobre la realidad sino sobre la experiencia de la realidad» (Sobejano 1986: 104). Dudando a veces de esa realidad representada por la prensa convencional, el lector se ve obligado a buscar otra interpretación de los sucesos, representada por el novelista. Este «views suspiciously most public figures and generally mistrusts "official facts"” (Kallan 1977: 3), de manera que la literatura testimonial sigue teniendo un papel importante y aparece para contradecir la historia oficial, contando la versión de la parte afectada.

En la España actual este tipo de novelas relata, ante todo, problemas sociales como son el paro, la delincuencia, la discriminación o la violencia de género, y se vincula estrechamente con el periodismo narrativo. Albert Chillón, destacando la convivencia de la literatura y el periodismo en una obra contemporánea, señala que el concepto de la literatura tradicional ha sufrido cambios radicales debido a industria de la comunicación en la cultura contemporánea:

La industria periodística, en concreto, ha transformado las pautas de producción, consumo y valoración social de la literatura: por un lado, contribuyendo a la formación de géneros nuevos -así, la novela realista del xix o el costumbrismo periodístico-literario de Dickens, Larra o Vilanova-; por otro, impulsando el desarrollo y la difusión de géneros literarios de carácter testimonial, como la prosa de viajes y el memorialismo; en último lugar generando modos singulares de escritura periodística-reportaje, crónica, ensayo, columna y artículo, guion audiovisual-que, en ciertos casos al menos, han alcanzado un alto valor artístico, hasta el punto de influir en la fisonomía de las formas literarias tradicionales (1999: 61).

Así, la verosimilitud del texto literario se ha convertido en la verdad verificable por el lector. Por otra parte, aunque mantiene la relación con la realidad que lo sustenta, el texto cuenta también con ese valor artístico del que habla Chillón, caracterizado por la adjetivación y distintas perspectivas de narrar. Se construyen escenas basadas en la descripción y el diálogo, creando ambientes y atmósferas correspondientes a los hechos. El diálogo aparece como el recurso clave para caracterizar a los personajes. Esa combinación supera los límites de literatura y periodismo en particular y forma una nueva simbiosis reflejada en el periodismo literario, que ya «no simula una realidad mediante la ficción, sino que da carácter de ficción a la realidad» (García de León 2000: 336).

La novela testimonial de la Espańa del siglo XIX, caracterizada por la dicotomía objetividad-subjetividad, la temática actual y socialmente comprometida, la 
actitud crítica y la tendencia a presentar relatos públicamente desconocidos o los que se oponen a la versión oficial, cuenta con una serie de rasgos particulares. El narrador toma una postura determinada, creando así un ambiente subjetivo y retando el statu quo establecido dentro de la versión oficial. Puede ser tanto testigo como el propio protagonista de los sucesos. En el segundo caso normalmente escribe su novela para advertir sobre un problema social del que ha sido víctima, para defender su postura y, en cierta medida, para desahogarse ante su público, que, con el desarrollo de nuevas herramientas para transmitir información, puede interactuar con el escritor (este último elemento caracteriza la literatura posnacional y refleja la función dual del género: debe informar y generar una participación activa del lector). Precisamente estos objetivos introducen las técnicas narrativas en la obra, haciendo la narración subjetiva. Asimismo, ya no suele relacionarse con la dictadura o la represión sino con los problemas de carácter social y los retos que el hombre moderno, siendo parte del mundo capitalista, afronta en su ámbito familiar o laboral. Suele narrar sobre sucesos previamente desconocidos o alternativos en cuanto a sus versiones oficiales y conocidas públicamente, construyendo otra realidad regida por leyes propias. Protagoniza personas reales cuya situación o estado presenta un problema comunitario o un fenómeno social, no solamente en España sino a nivel más amplio (rasgo característico de la literatura globalizada). Así, las obras Hay algo que no es como me dicen. El caso de Nevenka Fernández contra la realidad (2004) de Juan José Millás y No, mi general (2015) de Irene Lozano se ocupan de casos reales de acoso sexual que ocurrieron en el Ayuntamiento de Ponferrada y en las Fuerzas Armadas, respectivamente. La primera de ellas, a la que Fauquet (2011: 260) se refiere como «relato factual», presenta la necesidad del narrador-personaje de reconstruir la verdad a través de la investigación sobre la historia de una víctima que ha conseguido superar ese estatus denunciando al acosador. El compromiso ético del narrador, y con él del autor, permite presentar el caso Nevenka como plasmación singular de una denuncia contra la manipulación de los hechos por el discurso mediático y público y contra el machismo. Tal intencionalidad del texto hace concluir que «la escritura comprometida de Hay algo que no es como me dicen cobra la forma del arte de la sátira social y política, basada en el potencial ejemplificador del caso de Nevenka» (Fauquet 2011: 172).

Por otra parte, Jordi Soler en Los rojos de ultramar (2004) descubre la verdadera historia del exilio republicano y, relatando la experiencia de su abuelo, consigue recuperar la memoria colectiva de la historia real de su familia, que, por haber perdido la Guerra Civil, tuvo que abandonar el país para siempre y reiniciar su vida en México. Clara Usón, por su parte, después de una rigurosa investigación de tres años, escribe La hija del este (2013), donde relata la historia real del suicidio de la joven Ana Mladic, hija del general Ratko Mladic, durante la guerra de los Balcanes. Usón pasó tres años investigando sobre el asunto, recolectando el material y los testimonios de los que vivieron la historia de cerca. Así, la realidad, los datos y los personajes verídicos aparecen entrelazados con rumores y con los personajes inventados, con el fin de novelizar la historia y proteger la identidad de algunos de los interlocutores de la autora.

Marta Sanz escribe Daniela Astor y la caja negra (2013), donde se plantea preguntas sobre el significado de la liberación de la mujer y la relación de la transi- 
ción con la crisis actual. El tema de la transición personal de la mujer en la España de la Transición aparece también en su otra novela La lección de anatomía (2014), así como en La primera vez que no te quiero (2013) de Lola López Mondéjar y Naturaleza infiel (2008) de Cristina Grande. Las cuatro obras parten de los detalles autobiográficos (recuerdos, historias propias, la memoria personal, etc.) y referencias al mundo real (películas de cine, programas de televisión, anuncios publicitarios, entrevistas publicadas, etc.), pero sufren una transformación literaria, de tal forma que se sitúan, según afirma Valcárcel:

... en la frontera de lo autobiográfico y lo novelesco, lo verdadero - ¿verdadero?- y lo ficticio; autoficciones, autorretratos o autoginografías que se conciben desde una primera persona narrativa, desde un yo supuestamente confesional y/o testimonial que no oculta, sin embargo, el juego y artificio ficcional del mismo (2016: 16).

\section{A MODO DE CONCLUSIÓN}

A lo largo de su existencia, tanto las novelas de valor realista como testimonial, basándose en sucesos relevantes de su época o lugar, han representado textos social y culturalmente comprometidos que desafían la verdad oficial, de manera que su papel podría interpretarse como de denuncia. Siguiendo esa sociología de la literatura, como ha quedado señalado, la literatura globalizada actual ha permitido que estas obras no solo relaten historias sobre sus respectivos países, sino que también amplíen su temática a nivel internacional. Así, aparte de la presentación de temas bélicos (guerras, represiones, dictaduras, etc.) como una forma de preservar la memoria del pasado, surgen los de historias y retos personales que pueden atribuirse a cada sociedad, tanto individuales como colectivos.

Los autores de ambos tipos de novelas se preocupan por presentar lo real y optan por no esconder su postura acerca del tema que tratan. Intentan mostrar su presencia en la novela, ya sea porque realmente presenciaron los acontecimientos que relatan y quieren destacar el «yo» narrativo (casos de escritor-protagonista en novelas testimoniales), porque cuentan la experiencia de su interlocutor (casos de escritormediador en novelas testimoniales) o simplemente porque pretenden dejar constancia de sus reflexiones sobre la problemática presentada (casos de novelas realistas). En cualquier caso, se pierde la neutralidad del autor, quien prefiere tomar partido, ya sea de manera implícita o explícita, con la diferencia de que el tiempo, el espacio, los personajes y las acciones de las novelas de valor testimonial tienen un referente identificable fuera de la obra y la veracidad de hechos puede revisarse o corregirse, mientras que en un texto ficticio no es posible hacerlo ${ }^{4}$.

${ }^{4}$ En ese sentido, se considera necesario explicar dos principales nociones que se relacionan con dichos tipos de novelas (Ramírez 2014): «Verosimilitud es lo que en la literatura se llama realismo, otra formación del material que ofrece la realidad. Los datos que se ofrezcan al lector deben ser veraces bajo todo punto de vista. Los personajes son ficticios, pero su entorno no lo es. Compo- 
Precisamente esa razón específica que tienen los autores para involucrarse en el relato crea una diferencia entre estos dos tipos de novelas. Mientras la novela realista cuenta con un autor comprometido, la testimonial cuenta con uno implícito. Esto es, el primero siente la necesidad de relatar sobre fenómenos socialmente comprometidos, mientras que el segundo se implica directamente en la historia, narrando un hecho real concreto. De ahí que la primera pretende simular la verdad y representar un reflejo de lo real, mientras que la segunda relata la realidad misma ${ }^{5}$. En este segundo caso se distinguen dos tipos de narración: la directa (relatos de la propia experiencia del narrador) y la indirecta (relatos de las historias vividas por otras personas), aunque en ambas se observa la subjetividad del autor.

Finalmente, cabe concluir que los autores contemporáneos están comprometidos con la historia y con su tiempo, abordando las cuestiones inmutables de la humanidad. Los que se preocupan por narrar lo real y actual exploran constantemente la compleja realidad socioeconómica y quieren personalizar un tema global, pero también se interesan por los sentimientos y pensamientos más íntimos de sus personajes y tienen la necesidad de opinar sobre determinados problemas sociales e implicarse en la historia. Así, intentando cumplir con todas estas metas, el escritor termina modificando el concepto básico de la novela: «La búsqueda de una forma que se adecúe a un fenómeno de mundialización conlleva una renovación total de la novela que se convierte en algo más cercano a la visión o a la dicción que a la ficción o a la representación» (Gil 2012: 1432). Esa visión queda reflejada a través de dos conceptos literarios; la imaginación que pretende asimilarse a la verdad y la realidad que asume la forma de la ficción dentro de un texto narrativo.

ReCibido: septiembre de 2018; ACEPTADO: noviembre de 2018.

ner el escenario a partir de una noción básica y de ahí inventar el resto de la congruencia sin fallar en los detalles es la llave de la verosimilitud. Lo que precisa el lector es la credibilidad en la narración, que depende del grado de la verosimilitud». "Testimonio es una legítima recreación de hechos verídicos, basada en el examen de unos antecedentes reales. Son obras que se cińen estrictamente a una relación de esos hechos y todas las circunstancias anteriores y posteriores que los rodean, de manera que el escritor no puede inventar nada».

5 Chillón define a la realidad objetiva como «un lugar común un acuerdo intersubjetivo resultante del pacto entre las realidades subjetivas particulares» (1999: 26). 


\section{BIBLIOGRAFÍA}

Alonso, Santos (2011): «Narrativa versus literatura», en Geneviéve Champeau et al. (eds.), Nuevos derroteros de la narrativa española actual: veinte años de creación, Zaragoza: Prensas Universitarias de Zaragoza, 23-33.

Amar Sánchez, Ana María (1992): El relato de los hechos. Rodolfo Walsh: testimonio y escritura, Rosario: Beatriz Viterbo Editora.

BASANTA, Ángel (2016): «Reinvención de la novela social», Ínsula: La nueva novela española actual (1995-2015). Descubrimientos, perplejidades y estrategias DCCCXXXV-DCCCXXXvi: 3-7.

Birus, Hendrik (2003): «The Goethean Concept of World Literature and Comparative Literature», en Steven Tötösy de Zepetnek (ed.), Comparative Literature and Comparative Cultural Studies II, Indiana: Purdue University Press, 11-22.

CARCELÉN, Jean-François (2011): «Ficción documentada y ficción documental en la narrativa española actual: Ignacio Martínez de Pisón, Isaac Rosa», en Geneviéve Champeau et al. (eds.), Nuevos derroteros de la narrativa española actual. Veinte años de creación, Zaragoza: Prensas Universitarias de Zaragoza, 51-68.

Castany Prado, Bernat (2007): Literatura posnacional, Murcia: Universidad de Murcia.

Castañar, Fulgencio (2001): «Panorámica sobre el compromiso en la Segunda República», en Paul Aubert (ed.), La novela en España (siglos XIX-XX) LXVI, Madrid: Casa de Velázquez, 155-174.

Champeau, Geneviéve (2011): «Carta de navegar por Nuevos derroteros», en Geneviéve Champeau et al. (eds.), Nuevos derroteros de la narrativa española actual. Veinte años de creación, Zaragoza: Prensas Universitarias de Zaragoza, 9-19.

Chillón, Albert (1999): Literatura y periodismo. Una tradición de relaciones promiscuas, Barcelona: Universidad Autónoma de Barcelona.

Cortés, Carlos (2002): «Narrativa y globalización: el fin de la literatura universal y el hilo de Ariadna», en Eduardo Becerra (ed.), Desafios de la ficción viI, Alicante: Cuadernos de América sin Nombre, 45-56.

FAUQUet, Isabelle (2011): «Trayectorias ejemplares en Hay algo que no es como me dicen. El caso de Nevenka Fernández contra la realidad», en Amélie Florenchie e Isabelle Touton (eds.), La ejemplaridad en la narrativa española contemporánea (1950-2010), Madrid: Iberoamericana, Frankfurt am Main: Vervuert, 259-277.

Florenchie, Amélie (2011): «Isaac Rosa y la “escritura responable”», en Amélie Florenchie e Isabelle Touton (eds), La ejemplaridad en la narrativa española contemporánea (1950-2010), Madrid: Iberoamericana, Frankfurt am Main: Vervuert, 131-149.

García, Jordi y Domingo Ródenas (2011): Historia de la literatura española. Vol. 7. Derrota y restitución de la modernidad 1939-2010, en Gonzalo Pontón Gijón (coord.), José-Carlos MAINER (dir.), Madrid: Crítica.

GARCía DE LEÓN, Encarnación (2000): «Literatura periodística o periodismo literario», en Florencio Sevilla y Carlos Alvar (eds.), Actas del XIII Congreso de la Asociación Internacional de Hispanistas, Madrid: Castalia, 335-343.

GIL, Solange (2012): «Mundialización y literaturas nacionales. Cuando la mundialización provoca un nuevo realismo: el caso Daewo de François Bon», en Américo Cristófalo y Jerónimo Ledesma (eds.), Actas del V Congreso Internacional de Letras, Buenos Aires: Facultad de Filosofía y Letras, 1428-1433. 
Gullón, Germán (2004): «La novela en España: 2004. Un espacio para el encuentro», Ínsula LXxxVIII: 2 -4.

Gullón, Germán (2004a): «La novela española: 1980-2003», en Antonio Orejudo (coord.), En cuarentena: Nuevos narradores y criticos a principios del siglo XXI, Murcia: Universidad de Murcia, 15-37.

Gullón, Germán (2006): «La novela neorrealista (o de la generación X)», en Germán Gullón (dir.), Novela española contemporánea, Alicante: Biblioteca Virtual Miguel de Cervantes. URL: http://www.cervantesvirtual.com/nd/ark:/59851/bmcrr285; 20/10/2018.

Kallan, Richard A. (1977): «Tom Wolfe and the Uses of Argument», Annual Meeting of the Speech Communication Association LXIII: 1-26.

Mainer, José-Carlos (2005): Tramas, libros, nombres. Para entender la literatura española, 19442000, Barcelona: Anagrama.

Martínez Cachero, José María (1997): La novela española entre 1936 y el fin de siglo. Historia de una aventura, Madrid: Editorial Castalia.

Moragues Chazarra, María Ángeles (2013): «Reseña del libro La novela politica. Novelistas españolas del siglo XXI y compromiso histórico de Francisco Javier Díez de Revenga», Signa. Revista de la Asociación Española de Semiótica xxir: 749-751. URL: http://revistas.uned.es/index. php/signa/article/view/6376/6109; 19/07/2018.

Navajas, Gonzalo (2002): La narrativa española en la era global. Imagen. Comunicación. Ficción, Barcelona: EUB.

Navajas, Gonzalo (2005): «La historia y la literatura española posnacional», Studi Ispanici I, Roma: Instituti Editorial e Poligrafici e Internazionali, 255-265.

NúÑEz, Luis Pablo (2011): «Los grupos editoriales españoles y su influencia en la creación de los cánones literarios actuales», en Ana CABELlo et al. (eds.), En los márgenes del canon: aproximaciones a la literatura popular y de masas escrita en español (siglos 20 y 21), Madrid: Consejo Superior de Investigaciones Científicas, 31-50.

Orsini-SAILlET, Catherine (2011): «Ejemplaridad y ambigüedad en la obra novelesca de Rafael Chirbes», en Amélie Florenchie e Isabelle Touton (eds.), La ejemplaridad en la narrativa española contemporánea (1950-2010), Madrid: Iberoamericana, Frankfurt am Main: Vervuert, 77-94.

PAntel, Alice (2016): «De la generación Nocilla a la literatura mutante», Ínsula: La nueva novela española actual (1995-2015). Descubrimientos, perplejidades y estrategias DCCCXXXV-DCCCXXXVI: 32-35.

Pozuelo Yvancos, José María (2014): «La novela española del siglo xxi y el fin de un ciclo histórico», en Christian Lagarde y Philippe Rabaté (eds.), HispanismeS III: 438-450. URL: http://hispanistes.fr/images/PDF/HispanismeS/Hispanismes_3/SHF\%20HispanismeS\%203\%20 POZUELO\%20YVANCOS\%20Jose\%20Maria.pdf; 02/08/2018.

Pozuelo Yvancos, José María (2014a): Novela española del siglo XXI, Murcia: Universidad.

Pozuelo Yvancos, José María (2016): «Formas de la distopía: Isaac Rosa, Lara Moreno y Andrés Ibáńez», Ínsula: La nueva novela española actual (1995-2015). Descubrimientos, perplejidades y estrategias DCCCXXXV-DCCCXXXVI: 8-11.

Ramírez, Sergio (2014): El viejo arte de mentir. 1. ${ }^{a}$ sesión, Alicante: Biblioteca Virtual Miguel de Cervantes, [seminario]. URL: http://www.cervantesvirtual.com/obra/el-viejo-arte-de-mentir-1-sesion/; 22/07/2018. 
Ronen, Ruth (2010): «Theories of Realism», en David Herman, Manfred Jahn and Marie-Laure Ryan (eds.), Routledge Encyclopedia of Narrative Theory, 1st edition: 2005, London and New York: Taylor \& Francis e-Library, 486-491.

Scharam, Heike (2013): El tiempo y el ser en Javier Marias. El «Ciclo de Oxford» a la luz de Bergson y Heidegger, Amsterdam: Rodopi.

Sobejano, Gonzalo (1986): «Testimonio y poema en la novela española contemporánea», en I.A. David Kossoff et al. (eds.), Actas del VIII Congreso de la Asociación Internacional de Hispanistas, Madrid: Ediciones Istmo, 89-115.

VALCÁRCEL, Carmen (2016): «Historias en transición», Ínsula: La nueva novela española actual (19952015). Descubrimientos, perplejidades y estrategias DCCCXXXV-DCCCXXXVI: 16-18.

VAlls, Fernando (2003): La realidad inventada. Análisis crítico de la novela española actual, Barcelona: Crítica.

VALls, Fernando (2016): «La nueva novela de un país difícil», Ínsula: La nueva novela española actual (1995-2015). Descubrimientos, perplejidades y estrategias DCCCXXXv-DCCCXxxvi: 2-3. 